\title{
Degradación ruminal en bovinos de la proteína bruta de Paspalum notatum a diferentes edades de rebrote y estaciones del año
}

\author{
Slanac, A.L.'; Kucseva, C.D. ${ }^{2}$; Balbuena, O. ${ }^{2,3}$; Rochinotti, D. ${ }^{4}$ \\ ${ }^{1}$ Cátedra de Fisiología, ${ }^{3}$ Cátedra de Nutrición y Alimentación, Facultad de Ciencias Veterinarias, UNNE, \\ Sargento Cabral 2139, Corrientes (3400), Argentina. ${ }^{2}$ INTA Colonia Benítez (Chaco). \\ ${ }^{4}$ INTA Mercedes (Corrientes). E-mail: alslanac@vet.unne.edu.ar.
}

\begin{abstract}
Resumen
Slanac, A.L.; Kucseva, C.D.; Balbuena, O.; Rochinotti, D.: Degradación ruminal en bovinos de la proteína bruta de Paspalum notatum a diferentes edades de rebrote y estaciones del año. Rev. vet. 24: 2, 119-123, 2013. Con el objetivo de evaluar la degradación ruminal de la proteína bruta (PB) de Paspalum notatum (pasto horqueta) en el rumen de bovinos en distintas épocas del año, se recolectaron muestras de $5 \mathrm{~cm}$ de altura de dicha pastura, a los 15 , 30 y 45 días de rebrote. Para valorar la degradación de PB se utilizó la técnica de suspensión in situ de bolsas de dacrón, que fueron incubadas durante $0,3,6,12,24,48,72$ y $120 \mathrm{~h}$ en el rumen de novillos cruza cebú de $550 \mathrm{~kg}$ de peso, provistos de fístula ruminal, Una muestra del material original y las bolsitas del in situ posterior a la incubación se procesaron en laboratorio para la estimación de la PB. Los datos se ajustaron con el modelo propuesto por Orskov y McDonald. Los parámetros de la curva de degradación y la degradabilidad efectiva fueron analizados mediante el procedimiento GLM del paquete estadístico SAS. Los resultados obtenidos de la degradabilidad ruminal de PB para el rebrote de 15, 30 y 45 días, mostraron que la fracción soluble fue diferente en las distintas estaciones del año. La fracción potencialmente degradable, la tasa de degradación y la degradabilidad ruminal efectiva solo se diferenciaron $(\mathrm{p}<0,05)$ en el corte de 45 días. No se encontraron diferencias en los demás parámetros de la cinética ruminal, lo cual sugiere que la técnica utilizada no fue sensible para diferenciar el efecto de los tiempos de rebrote y las estaciones del año.
\end{abstract}

Palabras clave: bovino, rumen, proteína bruta, Paspalum notatum, degradabilidad.

\begin{abstract}
Slanac, A.L.; Kucseva, C.D.; Balbuena, O.; Rochinotti, D.: Ruminal degradation of crude protein from Paspalum notatum of different age of regrowth and seasons of the year in cattle. Rev. vet. 24: 2, 119-123, 2013. To evaluate parameters of ruminal degradation of crude protein (CP) in Paspalum notatum, samples of 15, 30 and 45 days of re-growth were cut at $5 \mathrm{~cm}$ height at each season of the year. Rumen-cannulated steers of $550 \mathrm{~kg}$ body weight were used to run in situ procedure. Incubation times were: 0, 3, 6, 12, 24, 48, 72 and $120 \mathrm{~h}$. Samples were analyzed for CP and data were fitted to Orskov y McDonald model. Resulting degradation parameters as well as effective CP degradation were analyzed by the GLM procedure of SAS package. Only the soluble fraction differed among seasons. Potentially degradable fraction, degradation rate and effective ruminal degradation were different only at 45 days of re-growth. Other $\mathrm{CP}$ ruminal degradation parameters were not affected by days of re-growth or season of the year, suggesting that the method may not be adequate for detecting effect of re-growth and season.
\end{abstract}

Key words: cattle, rumen, crude protein, Paspalum notatum, degradability.

\section{INTRODUCCIÓN}

Los nuevos sistemas de alimentación para bovinos, reconocen la importancia que tiene la degradación de la proteína del alimento en el rumen, para poder estimar la cantidad de ésta realmente digerida en el intes-

Recibido: 3 julio 2013 / Aceptado: 23 agosto 2013 tino delgado ${ }^{28}$. Indagar las curvas de dilución de las proteínas conduciría a conocer el estado nutricional de la planta en diferentes condiciones ambientales de crecimiento, lo cual permite la evaluación simultánea de la producción de materia seca y el contenido de proteína en los pastos, resolviendo el problema de la relación negativa entre ambos factores ${ }^{8}$. La edad de corte es un factor que contribuye a la determinación de la produc- 
ción y calidad de forraje, pues el envejecimiento de la planta reduce el tenor de humedad y consecuentemente aumenta la producción de materia seca ${ }^{24}$.

El método in situ de degradabilidad ruminal es eficaz para valorar la digestión en el rumen. Consiste en introducir bolsas de dacrón (material indigestible) con una cantidad específica de alimento en el rumen de animales fistulados, e incubarlos durante distintos períodos. El análisis de la información se hace ajustando los datos de desaparición de la fracción estudiada a una ecuación exponencial, la cual permite calcular constantes para las tasas de degradación y cuantificar la degradación ruminal de las diferentes fracciones del alimento ${ }^{20}$. La técnica in situ se usa frecuentemente para investigar la dinámica de la fermentación ruminal de los alimentos, permitiendo apreciar la cuantía y el ritmo de utilización de los componentes del alimento durante el proceso fermentativo ${ }^{18}$.

La degradabilidad de la proteína de los forrajes depende de las formas proteínicas de reserva ${ }^{30}$, de su localización en el interior de las paredes celulares ${ }^{29}$, de las características físicas y químicas del propio forra$\mathrm{je}^{2}$, de la estación del año ${ }^{11}$, del grado de lignificación ${ }^{4}$, de la especie vegetal ${ }^{11}$ y del tipo de conservación ${ }^{25}$ . La altura del pasto y el tipo de pastoreo son factores que inciden sobre la degradación ruminal. El pasto no es estático a lo largo de su ciclo productivo, lo cual dificulta la valoración del grado de degradación, su posterior utilización y por añadidura su predicción ${ }^{26}$.

La proteína se encuentra en el alimento como proteína verdadera o como nitrógeno no proteico (NNP). Por acción de las bacterias ruminales el NNP y las proteínas dan lugar a la formación de amoníaco $\left(\mathrm{NH}_{3}\right)$ y cadenas carbonadas. Si hay energía disponible, el $\mathrm{NH}_{3}$ es utilizado para la síntesis de proteína bacteriana. Existe una fracción de proteína que atraviesa el rumen rumbo al intestino sin ser alterada, siendo digerida más adelante por las enzimas intestinales. Ello implica que la proteína que arriba al intestino proviene de la suma de la proteína bacteriana más la no-degradable del alimento.

La fuente más importante de nitrógeno $(\mathrm{N})$ para los microorganismos ruminales procede normalmente de la proteína de la ración y del NNP. La microflora ruminal es altamente proteolítica, por lo cual gran parte de la proteína que llega al rumen es degradada hasta péptidos y aminoácidos, la mayoría de los cuales son posteriormente desaminados ${ }^{22}$.

Varios métodos pueden ser utilizados para estimar degradabilidad ruminal de proteínas, incluyendo la fermentación in saco e in vitro, así como los procesos enzimáticos ${ }^{16}$. La desaparición in saco es usada frecuentemente para estimar la proteína no degradable, pero este método adolece del problema de la influencia de la contaminación provocada por la proteína microbiana. El $\mathrm{N}$ proporcionado por las bacterias debería ser restado como $\mathrm{N}$ residual o no degradable ${ }^{27}$. La técnica in situ es fácil y de rápida ejecución, requiere pequeña cantidad de muestra, permite el contacto íntimo con el ambiente ruminal, no existiendo una mejor forma de simulación del rumen ${ }^{6}$; a pesar de ello, el alimento no está sujeto a todos los eventos digestivos, como la masticación, rumiación y tasa de pasaje ${ }^{18}$.

Otro problema potencial que se debería tener en cuenta en el procedimiento in saco es la suposición que la proteína, por ser soluble atraviesa la bolsa siendo degradada instantáneamente ${ }^{12}$. A pesar de que existen varias técnicas para estimar la degradabilidad ruminal de la proteína de los forrajes, el método más popular es el de la bolsa in situ ${ }^{19}$. La proteína microbiana debe ser cuantificada en duodeno o con el método in situ, para medir con precisión la proteína de escape; normalmente se utilizan purinas como marcadores de la proteína microbiana ${ }^{9}$.

El objetivo del trabajo fue evaluar en distintas épocas del año y a diferentes edades de rebrote, la cinética de la degradación ruminal de la proteína bruta de Paspalum notatum (pasto horqueta) en rumen de bovinos alimentados con pastura natural.

\section{MATERIAL Y MÉTODOS}

El material vegetal evaluado fue recolectado en un campo del nordeste argentino. Previo corte de limpieza con guadañadora mecánica y retiro del material cortado, las muestras de $P$. notatum fueron tomadas por medio de cortes con tijeras a $5 \mathrm{~cm}$ de altura, en todo el material disponible en condición de pastoreo, dentro de un marco de $50 \times 50 \mathrm{~cm}$. Los cortes se realizaron a los 15,30 y 45 días de rebrote. Una vez pesadas, las muestras se colocaron en bolsas de papel y fueron secadas en estufa de aire forzado a $55^{\circ} \mathrm{C}$ durante $72 \mathrm{~h}$, posteriormente fueron pesadas y luego molidas con molino de cuchillas con mallas de $2 \mathrm{~mm}$, colocándolas en cajas para su posterior análisis. Para medir la desaparición de la proteína bruta se utilizaron dos novillos cruza cebú de $550 \mathrm{~kg}$ de peso provistos de fístula ruminal, mantenidos en potreros con pastura natural. Los animales recibieron ad libitum un suplemento mineral que contenía $12 \% \mathrm{Ca}, 8 \% \mathrm{P}$ y microelementos vehiculizados en sal común.

Para la medición de la degradabilidad ruminal se utilizó la técnica de suspensión in situ de bolsas de dacrón ${ }^{21}$. En cada bolsa de $9,5 \times 18 \mathrm{~cm}$, con una porosidad de $50 \mu \mathrm{m}$, se colocaron $5 \mathrm{~g}$ del material seco de la pastura. Las bolsas fueron introducidas secuencialmente en el rumen en los siguientes tiempos: 120; 72; $48 ; 24 ; 12 ; 6 ; 3$ y 0 horas. Transcurrido el tiempo de incubación, las bolsas fueron retiradas del rumen y sumergidas en agua fría por $5 \mathrm{~min}$, para luego ser lavadas con agua corriente. Por último fueron secadas en horno a $55^{\circ} \mathrm{C}$ durante $72 \mathrm{~h}$ y posteriormente pesadas.

Los datos obtenidos de la degradación de la proteína bruta fueron ajustados al modelo propuesto por Orskov y McDonald: PB $\%=a+b\left(1-\exp ^{-c t}\right)$, donde PB \%: degradabilidad de la PB al tiempo "t" \%; "a" es la fracción soluble; "b" la fracción lentamente degradable; "c" la tasa de degradación de b, en horas; " $t$ " el tiempo 
de incubación en rumen, en horas y "e" la base de los logaritmos naturales. Se calculó además la degradabilidad efectiva de acuerdo a la ecuación de los mismos autores: $\mathrm{DE} \%=\mathrm{a}+\left[\left(\mathrm{b}^{*} \mathrm{c}\right) /(\mathrm{c}+\mathrm{kp})\right]$ donde $\mathrm{DE} \%$ es la degradabilidad efectiva; a, b y c son los mismos de la ecuación anterior, y $\mathrm{kp}$ es la tasa de pasaje (2 y $4 \%$ / hora) ${ }^{5}$.

Se utilizó un diseño completamente aleatorizado con un arreglo factorial: 2 (pasturas) x 3 (cortes) x 4 (estaciones), con 2 repeticiones (en dos animales). Se estimó la variancia de los parámetros de degradación $\mathrm{a}, \mathrm{b}, \mathrm{c}$, la degradación efectiva (sumatoria de $\mathrm{a}+\mathrm{b}$ ) y la tasa de degradación (kd). Se analizó el efecto de la edad de rebrote sobre la degradabilidad mediante análisis de varianza (ANOVA, procedimiento de modelos lineales generales GLM del paquete estadístico SAS $)^{27}$. Para la comparación de medias se efectuó test de Tukey. Se estipuló un riesgo alfa de $5 \%(\mathrm{p}<0,05)$.

\section{RESULTADOS Y DISCUSIÓN}

Las fracciones solubles de degradación rápida (a) fueron en general bajas, lo que aparentemente se debió al procedimiento del lavado, como pudo observarse para el rebrote de 15 días en el invierno (6,97\%); 30 días para la estaciones primavera $(3,62 \%)$ y verano $(7,32 \%)$; en otoño $(15,49 \%)$ y en primavera $(12,49 \%)$ para el rebrote de 45 días. Sin embargo, el potencial de degradación $\mathrm{a}+\mathrm{b}$ mostró valores significativamente mayores. Diferentes autores reportan la estrecha relación entre la solubilidad de la PB y su degradabilidad ${ }^{1}$. En general, la mayor solubilidad y degradabilidad de PB está asociada a un mayor nivel de amonio en el rumen y éste contribuye al incremento de la actividad de las bacterias ruminales, maximizando el consumo de dietas ricas en fibra ${ }^{14}$.

La degradabilidad inicial de PB de $P$. notatum presentó diferencias significativas para las tres edades de rebrote estudiadas. No obstante, se encontró una tendencia decreciente para este parámetro conforme avanzó la edad de la planta en el otoño, lo cual se debería al incremento de las estructuras de sostén y de pared celular que acompañan a su madurez, limitando el acceso de las proteasas al citoplasma, que es donde se encuentra la mayoría de la proteína potencialmente degradable. Este comportamiento es semejante al observado por otros autores ${ }^{7,10}$, lo que explica porqué los follajes jóvenes tienden a poseer mayores valores de $\mathrm{PB}$ en comparación con los de edades superiores ${ }^{5}$.

En la Tabla 1 se resumen los resultados obtenidos para la degradabilidad ruminal de $\mathrm{PB}$ en el rebrote de 15 días. El análisis de la varianza detectó diferencias significativas entre épocas del año para la fracción soluble $(p<0,02)$. Se puede apreciar un similar comportamiento de este parámetro en otoño, verano y primavera. El mayor porcentaje de degradación se registró en otoño $(39,92 \%)$ y el menor durante el invierno (6,97\%). No se detectaron diferencias significativas en la fracción de degradación lenta (b), en la tasa de degradación (c) y en la degradación ruminal (DR al 2 y 4\%).

La cinética de degradación ruminal de $\mathrm{PB}$, para los distintos tiempos de incubación en el rebrote de 15 días, registró efectos significativos $(\mathrm{p}<0,05)$. La hora cero $(\mathrm{p}=0,022)$, mostró una alta solubilidad para otoño $(44,41 \%)$, respecto del verano $(34,47 \%)$, primavera $(28,14 \%)$ e invierno $(7,82 \%)$. En la tercera hora de incubación $(\mathrm{p}=0,008)$ el comportamiento fue semejante con valores de 43,$87 ; 39,41 ; 26,21$ y $13,72 \%$ para otoño, verano, primavera e invierno respectivamente. La hora doce $(\mathrm{p}=0,031)$ acusó una mayor solubilidad en la estación estival (42,18\%) vs el otoño (40,48\%), primavera $(32,43 \%)$ e invierno $(18,48 \%)$. A las setenta y dos horas de incubación $(p=0,012)$, la época con mayor solubilidad resultó ser primavera $(55,26 \%)$, seguida del otoño $(46,32 \%)$ verano $(45,36 \%)$ e invierno $(35,73 \%)$. Los horarios 6, 24, 48 y 120 del in situ no fueron estadísticamente diferentes.

En la Tabla 2 se resumen los resultados obtenidos para la degradabilidad ruminal de PB en el rebrote de 30 días. El análisis de la varianza detectó diferencias significativas entre estaciones para la fracción soluble

Tabla 1. Parámetros de degradabilidad ruminal in situ de PB de P. notatum (pasto horqueta) a 15 días de rebrote en distintas estaciones del año $(\overline{\mathrm{x}})$.

\begin{tabular}{|c|c|c|c|c|c|c|}
\hline \multirow{2}{*}{ parám. } & \multicolumn{4}{|c|}{ época del año } & \multirow{2}{*}{ EE } & \multirow{2}{*}{ p } \\
\hline & otoño & invierno & primavera & verano & & \\
\hline a (\%) & $39,92^{\mathrm{a}}$ & $6,97^{b}$ & $27,67^{\mathrm{ab}}$ & $33,84^{a}$ & 4,23 & 0,02 \\
\hline b $(\%)$ & 25,82 & 30,64 & 37,69 & 13,36 & 1,09 & 0,47 \\
\hline c $(\% / h)$ & 7,00 & 6,70 & 5,40 & 8,90 & 0,60 & 0,51 \\
\hline DR $2 \%$ & 55,39 & 30,38 & 54,29 & 44,58 & 6,54 & 0,15 \\
\hline DR $4 \%$ & 51,25 & 25,97 & 48,65 & 42,89 & 5,93 & 0,12 \\
\hline
\end{tabular}

parám: parámetros de cinética ruminal; a: fracción soluble; b: fracción de degradación lenta; c: tasa de degradación b; DR: degradación ruminal. EE: error estándar; p: probabilidad. En cada fila, letras distintas indican diferencias significativas entre medias (test de Tukey, $\mathrm{p}<0,05$ ).

Tabla 2. Parámetros de degradabilidad ruminal in situ de PB de $P$. notatum (pasto horqueta) a 30 días de rebrote en distintas estaciones del año $(\overline{\mathbf{X}})$.

\begin{tabular}{|c|c|c|c|c|c|c|}
\hline \multirow{2}{*}{ parám. } & \multicolumn{4}{|c|}{ época del año } & \multirow{2}{*}{$\mathrm{EE}$} & \multirow{2}{*}{$\mathrm{p}$} \\
\hline & otoño & invierno & primavera & verano & & \\
\hline a (\%) & $35,76^{\mathrm{a}}$ & $20,73^{b}$ & $3,62^{\mathrm{b}}$ & $7,36^{\mathrm{b}}$ & 3,22 & 0,01 \\
\hline b (\%) & 32,05 & 31,78 & 68,81 & 64,53 & 14,13 & 0,25 \\
\hline c $(\% / h)$ & 5,20 & 2,30 & 7,40 & 5,00 & 0,20 & 0,53 \\
\hline DR 2\% & 57,06 & 36,64 & 58,25 & 51,36 & 15,45 & 0,75 \\
\hline DR 4\% & 52,15 & 31,57 & 49,02 & 41,91 & 14,41 & 0,76 \\
\hline
\end{tabular}

parám: parámetros de cinética ruminal; a: fracción soluble; b: fracción de degradación lenta; c: tasa de degradación b; DR: degradación ruminal. EE: error estándar; p: probabilidad. En cada fila, letras distintas indican diferencias significativas entre medias (test de Tukey, $\mathrm{p}<0,05$ ). 
Tabla 3. Parámetros de degradabilidad ruminal in situ de PB de $P$. notatum (pasto horqueta) a 45 días de rebrote en distintas estaciones del año $(\overline{\mathbf{x}})$.

\begin{tabular}{|c|c|c|c|c|c|c|}
\hline \multirow{2}{*}{ parám. } & \multicolumn{4}{|c|}{ época del año } & \multirow{2}{*}{$\mathrm{EE}$} & \multirow{2}{*}{ p } \\
\hline & otoño & invierno & primavera & verano & & \\
\hline $\mathrm{a}(\%)$ & $15,49^{\mathrm{ab}}$ & $27,98^{\mathrm{a}}$ & $12,49^{b}$ & $48,90^{\mathrm{c}}$ & 2,61 & 0,002 \\
\hline$b(\%)$ & $66,46^{\mathrm{a}}$ & $34,80^{\mathrm{b}}$ & $40,14^{\mathrm{ab}}$ & $24,81^{\mathrm{b}}$ & 4,89 & 0,01 \\
\hline c $(\% / h)$ & 1,00 & 2,90 & 4,80 & 7,10 & 0,20 & 0,37 \\
\hline DR $2 \%$ & $39,00^{\mathrm{a}}$ & $46,67^{\mathrm{a}}$ & $40,55^{\mathrm{a}}$ & $66,36^{\mathrm{b}}$ & 2,14 & 0,01 \\
\hline DR 4\% & $29,77^{\mathrm{a}}$ & $41,00^{\mathrm{a}}$ & $34,16^{\mathrm{a}}$ & $62,73^{\mathrm{b}}$ & 2,96 & 0,01 \\
\hline
\end{tabular}

parám: parámetros de cinética ruminal; a: fracción soluble; b: fracción de degradación lenta; c: tasa de degradación b; DR: degradación ruminal. EE: error estándar; p: probabilidad. En cada fila, letras distintas indican diferencias significativas entre medias (test de Tukey, $\mathrm{p}<0,05$ ).

$(\mathrm{p}<0,01)$, donde se pudo apreciar comportamiento semejante en invierno, verano y primavera. El mayor porcentaje de degradación se observó en el otoño (35,76\%) y el menor en la primavera (3,62\%). El análisis estadístico reveló que no se detectaron diferencias significativas $(p>0,05)$ para la fracción de degradación lenta (b), tasa de degradación $(\mathrm{kd}) \mathrm{y}$ degradación ruminal (DR al 2 y $4 \%$ ).

La cinética de degradación de PB para el rebrote de 30 días, en los distintos horarios de incubación y diferentes estaciones, mostró una tendencia a ser diferente $(\mathrm{p}=0,06)$. La hora 0 presentó mayor solubilidad en otoño $(38,17 \%)$, con respecto al invierno $(21,55 \%)$, verano $(14,66 \%)$ y primavera $(6,78 \%)$. En cambio a la hora 12 , el menor porcentaje de degradación, se registró en verano $(7,07 \%)$, manteniendo valores similares para otoño $(38,95 \%)$, invierno $(21,39 \%)$ y primavera $(16,90 \%)$.

Los horarios 3, 6 y $24 \mathrm{~h}$ mostraron valores estadísticamente diferentes $(\mathrm{p}=0,02)$; la incubación de 3 horas reveló que el otoño fue la estación del año con mayor degradación (31,57\%), mientras que invierno y verano se comportaron muy parecidos $(23,10$ y $17,72 \%$ respectivamente). En la primavera se observó el valor más bajo de degradabilidad (6,32\%). A las 6 horas de incubación ( $\mathrm{p}=0,01)$, otoño e invierno arrojaron valores estadísticamente parecidos $(32,87$ y $26,66 \%$ respectivamente), diferentes a los obtenidos para primavera (13,06\%) y verano (5,38\%). El in situ de la hora 24, mostró el mayor valor de degradabilidad otoñal $(44,21 \%)$, valores intermedios para invierno y primavera $(37,34$ y $35,47 \%$ ), obteniéndose la más baja solubilidad en verano $(16,67 \%)$.

Los demás horarios de incubación no presentaron diferencias estadísticas significativas. Se observó similar comportamiento en los distintos horarios (48, $72 \mathrm{y}$ 120 horas de incubación), donde la cinética reveló que la mayor degradabilidad la presentó el otoño seguido por primavera y verano. La de menor degradabilidad se registró en la estación invernal. De acuerdo a los resultados obtenidos de la degradación de la $\mathrm{PB}$ en los cortes de 15 y 30 días de rebrote, los mismos podrían constituir factores limitantes para el consumo ${ }^{17}$, a tenor de lo citado por otros autores ${ }^{15}$.

En la Tabla 3 se resumen los resultados obtenidos para la degradabilidad ruminal de PB en el rebrote de 45 días, donde el análisis estadístico puso de relieve diferencias significativas $(\mathrm{p}<0,05)$ para la fracción soluble (a), fracción de degradación lenta (b) y degradación ruminal (DR). El análisis de la varianza no detectó diferencias significativas entre estaciones para la tasa de degradación $(\mathrm{p}<0,374)$. La fracción soluble presentó el mayor porcentaje de degradación en verano, diferenciándose de las otras estaciones.

La fracción potencialmente degradable fue mayor en la época otoñal, diferenciándose de las demás estaciones. En primavera se encontró una tasa de degradación similar a la del otoño. La tasa de degradación de $b$ fue mayor en primavera, si bien estadísticamente se asemejó a la de invierno, pero totalmente diferente a la del otoño, que presentó el porcentaje más bajo de degradación.

La degradación ruminal efectiva para las dos tasas ensayadas mostró ser mayor para verano, con un porcentaje superior al $62 \%$ con valores que oscilaron entre 29 y $47 \%$ para las otras épocas. Otros investigadores reportaron la estrecha relación entre solubilidad y degradabilidad de la PB ${ }^{1}$. En general, la mayor solubilidad y degradabilidad de PB está asociada a un alto nivel de amonio en rumen, lo cual contribuiría al incremento de la actividad microbiana ${ }^{14}$. La cinética de degradación en los distintos horarios de incubación, para el rebrote de 45 días, mostró ser diferente estadísticamente, a excepción de la hora 12, donde solo reveló una tendencia $(\mathrm{p}=0,099)$. Para el rebrote de 45 días la mayor solubilidad se presentó en la época estival, en todos los horarios (inicial $=48,99$ vs final $=71,59 \%$ ), seguida por el otoño (inicial $=22,03$ vs final $=61,78 \%$ ).

En cuanto a la composición química, no se observaron diferencias significativas en el porcentaje de proteína bruta. El valor más alto se encontró en el rebrote de 30 días de otoño e invierno y el de 45 días de verano (11,1\%), descendiendo a medida que aumentó la edad de rebrote $(10,9 ; 9,9 ; 8,3 \%$ para el corte de 45 días de otoño, invierno y primavera respectivamente). Esta tendencia no se manifestó en verano, donde el rebrote de 15 días mostró un 6\% de PB y mejoró el tenor para los cortes de mayor edad (6,2 y 11,1\% para rebrote de 30 y 45 días respectivamente).

En ensayos realizados con el fin de determinar el efecto de la edad de rebrote sobre el valor nutricional de Pennisetum purpureum cv King grass ${ }^{3}$, se observaron en rebrotes 60,75 y 90 días, valores de PB de 9,$56 ; 8,70$ y $8,42 \%$ respectivamente. Tales hallazgos fueron similares a los reportados para $P$. purpureum CT $115^{23}$, coincidiendo con los resultados de la presente investigación, donde el contenido proteico varió de forma inversa respecto de lo ocurrido para materia seca ${ }^{8}$. No obstante, a pesar de que está descripta una disminución lineal de $0,18 \%$ de proteína por cada día 
adicional de crecimiento ${ }^{13}$, en el presente trabajo se registró una tendencia cuadrática, en coincidencia con otros reportes ${ }^{3}$.

En conclusión, surge que la degradación ruminal de la proteína bruta de P. notatum no fue afectada por la estación y la edad de corte, según el método in situ. Se detectaron efectos de la edad de la planta y de las estaciones del año sobre algunos parámetros de degradación ruminal y sobre la degradabilidad efectiva, aunque de manera muy variada e inconsistente, lo cual sugiere que el método utilizado no sería el más adecuado para las condiciones en las que se realizó el presente ensayo.

\section{REFERENCIAS}

1. All T, Stobbs TH. 1980. Solubility of the protein of tropical pasture species an the rate of its digestion in the rumen. Anim Feed Sci Tech 5: 183-192.

2. Aufrere J, Cartailler D. 1988. Mise au point d'une method de laboratorie de prévision de la dégradabilité des protéines alimentaires des aliments concentrés dans le rumen. Ann Zootech 37: 255-270.

3. Chacon PA, Vargas CF. 2009. Digestibilidad y calidad del Pennisetum purpureum cv. King grass a tres edades de rebrote. Agron Mesoamericana 20: 399-408.

4. Deinum B. 1984. Chemical composition and nutritive value of herbage in relation to climate. Proceedings Tenth General Meeting of the European Grassland Federation, Moervegen, Norway, p. 338-350.

5. Devendra C. 1995. Composition and nutritive value of browse legumes. In: Tropical Animal Nutrition (D’Mello J, Devendra C, Ed), CAB International, UK, p. 49-66.

6. Evangelista AR, Junqueira EC, Teixeira JC, Porto G, Fonseca RT. 2002. Degradabilidade ruminal da materia seca e proteína bruta de cultivares de alfafa (Medicago sativa L.). Ciencia e Agrotecn 26: 1281-1288.

7. Homen M, Entrena I, Arriojas L, Ramia M. 2010. Biomasa y valor del pasto guinea (Megathyrsus maximus) en diferentes períodos del año en la zona de bosque húmedo tropical (Barlovento, Miranda, Venezuela). Zootec Trop 28: 255.

8. Juárez J, Bolaños ED. 2007. Las curvas de dilución de la proteína como alternativa para la evaluación de pastos tropicales. Univ \& Ciencia 23: 81-90.

9. Klopfenstein TJ, Mass RA, Creighton KW, Patterson HH. 2001. Estimating forage protein degradation in the rumen. J Anim Sci 79: 208-217.

10. Lara C, Oviedo LE, Betancur CA. 2010. Efecto de la época de corte sobre la composición química y degradabilidad ruminal del pasto Dichantium aristatum (Angleton). Zootec Trop 28: 275-281.

11. Le Goffe P, Verite R, Peyraud JL. 1993. Influence de l'espece et de la saison sur la dégradabilité de làzote des fourrages verts dans le rumen. Ann Zootech 42: 3-15.

12. Mahadevan S, Erfle JD, Sauer FD. 1980. Degradation of soluble and insoluble proteins by Bacteroides amylophilus protease and by rumen microrganisms. J Anim Sci 50: 723-728.

13. Márquez F, Sánchez J, Urbano D, Dávila C. 2007. Evaluación de la frecuencia de corte y tipos de fertilización so- bre genotipos de pasto elefante (Pennisetum purpureum). 1. Rendimiento y contenido de proteína. Zootec Trop 25: 253-259.

14. Meherez AZ, Orskov ER, McDonald P. 1977. Rates of rumen fermentation in relation to ammonia concentration. British J Nutr 38: 437.

15. Méndez-Cruz A. 1981. Evaluación nutritiva de gramíneas forrajeras tropicales. Alpa Mem 16: 90.

16. Michalet B, Ould MY. 1992. Influence of hay making on in situ nitrogen degradability of forages in cows. J Dairy Sci 75: 782.

17. Minson DJ, Milford R. 1967. The voluntary intake and digestibility of diets containing different proportions of legume and nature pangola grass. Austr J Exp Agr Anim Husb 7: 546-551.

18. Nocek JE. 1988. In situ and other methods to estimate ruminal protein and energy digestibility: a review. J Dairy Sci 71: 2051.

19. Olaisen V, Mejdell T, Volden H, Nesse N. 2003. Simplified in situ method for estimating ruminal dry matter and protein degradability of concentrates. J Anim Sci 81: 520-528.

20. Orskov ER, McDonald IM. 1979. Estimation of protein degradability in the rumen from incubation measurement weighted according to rate of passage. J Agric Sci 96: 499503.

21. Orskov ER, Hovell FD, Mould F. 1980. The use of the nylon bag technique for the evaluation of feedstuffs. Trop Anim Prod 5: 195-213.

22. Orskov ER. 1988. Nutrición proteica de los rumiantes, Acribia, Zaragoza, 178 p.

23. Ramirez J, Verdecia D, Leonard I. 2008. Rendimiento y caracterización química del Pennisetum Cuba CT 169 en un suelo pluvisol. Rev Electr Vet 9: 5. Disponible en: http:// www.veterinaria.org/revista/redvet/n050806.pdf.

24. Sa JF, Pedreira MS, Silva FF, Bonomo P, Figueredo MP, Menezes, DR, Almeida TB. 2010. Fraccionamiento de carbohidratos e protínas de gramíneas tropicais cortadas em tres idades. Arq Bras Med Vet Zootec 62: 667-676.

25. Salcedo G, Sarmiento M. 1997. Degradabilidad ruminal de la alfalfa según el tipo de conservación. Actas XXXVII Reunión Científica de la Sociedad Española para el Estudio de los Pastos (SEEP), Sevilla, p. 463-468.

26. Salcedo G. 2000. Degradabilidad ruminal de la hierba en praderas aprovechadas bajo pastoreo rotacional en la zona costera de Cantabria. Invest Agr Prod Sanid Anim 15: $125-$ 135.

27. SAS Institute. 2008. Guide for personal computers, Version 9.2. Ed. SAS Institute Inc., Cary, North Carolina, USA.

28. Satter LD, Roffler RE. 1975. Nitrogen requirement and utilization in dairy cattle. J Dairy Sci 58: 1219-1237.

29. Tamminga S. 1983. Recent advances in our knowledge on protein digestion and absorption in ruminants. IV Int Symp Prot Metab \& Nutr., Clermont-Ferrand (France), p. 263-287.

30. Wallace RJ, Broderick GA, Brammal ML. 1987. Protein degradation by ruminal microorganisms from sheep fed dietary supplements of urea, casein, or albumin. Appl Environ Microb 53: 751-753. 